\title{
More Insight on Charcterization of Nano-sized Particles of Silver Powder and their Application in Antimicrobial Wound Dressing and Anti- inflammatory Efficacy
}

\author{
A. Hebeish, M.H. El-Rafie, M. A. EL-Sheikh, Amany \\ Seleem $^{*}$ and M. E. El-Naggar ${ }^{\#}$ \\ Textile Research Division, and * Department of Pharmacology, \\ National Research Centre, Giza, Egypt.
}

\begin{abstract}
D OWDERED silver nanoparticles (AgNPs) was successfully prepared through addition of $\mathrm{AgNO}_{3}$ to alkali dissolved starch. The latter was used as eco-friendly biopolymers which played the dual role as reducing and stabilizing agent followed by precipitation with ethyl alcohol. The as prepared AgNPs powders have the smallest size $(12-22 \mathrm{~nm})$, polydispersity $(0.163)$ as well as zeta potential $(-28 \mathrm{mv})$ indicating higher surface area, the highly distributed nanoparticles as well as long-term stability of their product. These powdered AgNPs were re-dispersed in distilled water and diluted to different concentrations (250, 125 and $60 \mathrm{ppm})$. The diluted solution of AgNPs was applied to cotton fabrics as per the pad-dry-cure technique. The antimicrobial, wound healing, anti-inflammatory as well as toxicity of cotton fabrics loaded with these three different concentrations of AgNPs colloidal solution were evaluated. AgNPs in three different states, viz., in the powder form, in aqueous solution and deposited onto cotton fabrics were characterized using the world-class facilities such as UV-Vis spectroscopy, Transmission Electron Microscopy (TEM), Particle size analyzer, Polydispersity index (PdI), Zeta potential (ZP) and Scanning Electron Microscopy connected with Energy Dispersive X-ray (SEM-EDX). Cotton fabrics containing 250 ppm AgNPs were more effective against different species of microorganisms than those of dressing containing 60 and $125 \mathrm{ppm}$ as indicated by the inhibition zone. Wound healing caused by dressing containing the highest content of AgNPs displayed the highest potent healing, with great similarity to the controlled cream (Dermazin). Moreover, the anti-inflammatory effect of $0.5 \mathrm{ml}$ dose AgNPs $(250$ $\mathrm{ppm}$ ) is nearly similar to $20 \mathrm{ml}$ dose of the reference drug (indomethacin). Also reported was that, the Minimum Inhibitory Concentration (MIC) for the produced AgNPs on subsequent experiments was $\leq 10 \mu \mathrm{g} / \mathrm{ml}$.
\end{abstract}

Silver was extensively used to control infections since ancient times. Nowadays, silver is finding wide- spread applications in medical domains ${ }^{(\mathbf{1})}$. Silver-based medical products were proven to be effective in retarding and preventing bacterial infections ${ }^{(2)}$. It is worthy reporting that there is an increasing interest toward the exploitation of silver nanoparticles technology in the development of

\footnotetext{
${ }^{\#}$ Corresponding author:

E.mail address: mehrez_chem@ yahoo.com; Tel: +20237831233; Fax: +20233363261
} 
bioactive biomaterials ${ }^{(3,4)}$. This development adresses combination of the relevant antibacterial properties of the metal with the peculiar performance of the biomaterial $^{(5-7)}$

Formulation of new pharmaceutical products, ${ }^{(8)}$ necessities the preparation of uniform nano-sized silver particles in terms of size and shape, as well as physical and chemical properties. There is much interest in finding ways to formulate new types of safe and cost-effective biocidal materials ${ }^{(7)}$. This is because resistance of bacteria to bactericides and antibiotics has increased in recent years due to the development of resistant strains. In addition, some antimicrobial agents are irritant and toxic.

Many new industries are involved in production of antibacterial gels loaded with $\operatorname{AgNPs}^{(9)}$. Materials and cloth can be made sterile by loading them with AgNPs. The sterile materials are badly needed in hospital, where often wounds are contaminated with microorganisms ${ }^{(10)}$. Reduction or prevention of infections is realized because AgNPs acts like antimicrobial agent ${ }^{(11)}$. AgNPs can be employed as effective growth inhibitors in various microorganisms. Thus, indeed, makes AgNPs applicable to diverse medical devices and antimicrobial control systems.

There is a huge enhancement in the surface area available for the microbe to be exposed when AgNPs are used. The action mechanism of AgNPs on microbes is neither fully understood nor well established. However, it was hypothesized that AgNPs can cause cell lysis or inhibits cell transduction ${ }^{(12)}$.

The present work have two-fold objective. The first was to prepare silver nanoparticles in the powder form with the smallest size using alkali dissolved starch as reducing and stabilizing agent followed by applying these particles to cotton fabrics. The second objective was to evaluate the AgNPs-treated cotton fabrics against Escherichia coli (E.Coli), Staphylococcus aureus (S. aureus) and Candida Albicans (C. Albicans) as well as in vivo wound healing. Evaluation of the anti-inflammatory activity of AgNPs colloidal solution in a known model of inflammation as well as their toxicological effect was monitored. Here too, mention should be made that the theme of the work under investigation is carried out to verify our previous work ${ }^{(13)}$ pertaining to synthesis of AgNPs in the powder form as well as to gain more information necessary to guarantee reproducibly of such synthesis. This is, of course, in addition to the two-fold objective outlined above.

\section{Materials and Methods}

\section{Materials}

AgNPs colloidal solution

The powdered AgNPs with smallest size (12-22 nm) were prepared according to conditions detailed later. This powder was dissolved in $100 \mathrm{ml} \mathrm{H}_{2} \mathrm{O}$ to give 
sized AgNPs colloidal solution with a concentration of $30000 \mathrm{ppm}$. This prepared colloidal solution was diluted to three different concentrations, namely, 250, 125 and $60 \mathrm{ppm}$ using distilled water at temperature of $25^{\circ} \mathrm{C}$.

\section{Cotton fabrics}

Mill desized-scoured-bleached cotton fabrics were used for monitoring the antimicrobial effect of colloidal silver on present thereon. Prior to the antimicrobial treatment, the fabric was cut into equal sized square pieces measuring $20 \mathrm{~cm} \times 20 \mathrm{~cm}$.

\section{Clinical isolates}

Three microbial clinical isolates namely, E.Coli, S. aureus and C. Albicans were supplied by Micro Analytical Center, Faculty of Science, Cairo University, Giza, Egypt. All microbial clinical isolates were maintained routinely on nutrient agar slants at $4^{\circ} \mathrm{C}$.

\section{Experimental Animals}

The rats of either sex, weighing 100- $120 \mathrm{~g}$ were used for in vivo studies and obtained from Animal Lab, National Research Centre, Dokki, Cairo. The experiments were conducted in accordance with the internationally accepted principles for laboratory animal use and the experimental protocols were approved by the Institutional Animal Ethical Committee. The rats were housed in polypropylene cages in standard environmental conditions, fed with standard rodent diet and water and libitum.

\section{Drugs}

Indomethacin was a kind gift from Memphis Pharmaceutical Co., Egypt. Carrageenan was purchased from Sigma Company. Dermazin was also purchaced from pharamaceutical markets, Cairo, Egypt.

\section{Methods}

Preparation of powdered AgNPs

Powdered silver nanoparticles (AgNPs) with a concentration of $30000 \mathrm{ppm}$ were prepared according to the optimum conditions: $5 \mathrm{~g}$ of native starch was added to $80 \mathrm{ml}$ sodium hydroxide solution $(30 \%$ based on weight of starch).The temperature of the solution was raised to $70^{\circ} \mathrm{C} .4 .72 \mathrm{~g}$ of $\mathrm{AgNO} 3$ dissolved in $20 \mathrm{ml} \mathrm{H}_{2} \mathrm{O}$ was slowly added to the above alkaline solution under higher stirring homogenizer. The reaction was kept for almost $60 \mathrm{~min}$ at $\mathrm{pH} 12$. Finally, $\quad 100 \mathrm{ml}$ absolute ethanol was added slowly to the above solution in order to precipitate the AgNPs in the powder form. The AgNPs powder was collected by centrifugation at $4500 \mathrm{rpm} / 15 \mathrm{~min}$. followed by decantation by $80 / 20$ ethanol/water to remove the unreacted components, then washed again by absolute ethanol, and finally dryed at ambient condition. 
Finishing of cotton fabrics with AgNPs

Samples of cotton fabrics were impregnated in AgNPs colloidal solution having different concentration $(60,125$ and $250 \mathrm{ppm})$ for 2 min followed by padding at a constant pressure to obtain $100 \%$ wet pickup. The treated cotton samples were dried at $70^{\circ} \mathrm{C}$ for $3 \mathrm{~min}$. The finished samples with the different concentration of AgNPs were used for further medical application. Untreated cotton fabrics were used as positive control.

\section{Characterization}

Ultra-violet visible (UV-Vis) spectroscopy: The formation of AgNPs in colloidal solution was monitored using UV-Vis spectral analysis (T80 spectrophotemeter). The spectra of the surface plasmon resonances of Ag NPs were recorded using a $\mathrm{UV}-\mathrm{V}$ is spectrophotometer at wavelengths between 250 to $600 \mathrm{~nm}$.

Transmission electron microscopy (TEM): The morphological examination of the nanoparticles was performed by transmission electron microscopy (TEM) on a JEOL (JEM-1230) Japan with an acceleration voltage of $120 \mathrm{kV}$. The particle size distribution of the Ag NPs obtained from TEM images were measured using Image J $1.45 \mathrm{~s}$ software, accurately by choosing at least 100 particles from different TEM micrographs.

Hydrodynamic size and zeta potential measurement of St-Ag NPs: The average particle size along with its PdI and the ZP of the nanoparticles were analysed by Dynamic light scattering (DLS) using a Zetasizer Nano ZS (Malvern Instruments, UK). Particle size and PdI measurements were performed at a scattering angle of $90^{\circ}$ and at a temperature of $25^{\circ} \mathrm{C}$. The samples for $\mathrm{ZP}$ were placed in a disposable zeta cell at a temperature of $25^{\circ} \mathrm{C}$. The measurement was repeated three times for each sample.

Scanning electron microscopy connected with energy dispersive $X$-ray $(S E M-E D X)$ : The surface morphology of cotton fabrics sample loaded with different concentrations of AgNPs was observed using SEM (JEOL 840 A) equipped with energy dispersive X-Ray spectroscopy (EDX) for the compositions analysis.

Antimicrobial activity by disc diffusion method: Standard well agar diffusion method was carried out to detect the activity of untreated and treated cotton fabrics with AgNPs at different concentration $(250 \mathrm{ppm}, 125 \mathrm{ppm}$ and $60 \mathrm{ppm}$ against the clinical microbial isolates (E.coli, S. aureus and $C$. albicans). In order to determine antimicrobial activities of these fabrics, the gar plates were prepared, sterilized and allowed to solidify. After solidification, plates were inoculated with bacterial and fungal cultures. Wells were made in plates containing nutrient agar medium seeded with $100 \mu \mathrm{l}$ of $24 \mathrm{hr}$ of each

Egypt. J. Chem. 56, No. 2 (2013) 
clinical isolate. Fabrics treated with AgNPs at different concentrations as well as the control, $100 \mu \mathrm{l}$ were placed in separate wells. The plates were left in refrigerator for $2 \mathrm{hr}$ then, incubated at $37{ }^{\circ} \mathrm{C}$ for $24 \mathrm{hr}$. The plates were examined for evidence of inhibition zone which appears as a clear area around the AgNPs treated samples of cotton fabrics. The diameter of such zones of inhibition was measured using a meter and the mean value for each organism was recorded and expressed in millimetre $(\mathrm{mm})$.

In vivo wound healing activity of AgNPs: Animals were anaesthetised by open mask method with anaesthetic ether and their backs were shaved with electric clippers ${ }^{(12)}$. They were placed in a mold in such a way that approximately $10 \%$ of their body surface area remained exposed. The exposed skin surface of each rat was immersed for $5 \mathrm{sec}$ in $90^{\circ} \mathrm{C}$ water, resulting in a grade II burned wound of $10 \%$ total body surface area. To prevent shock, the animals were resuscitated with intraperitoneal injection of $5 \mathrm{ml}$, saline solution. Group a, represents the wounded rats that were treated with the untreated cotton fabrics as control. Group b exhibits the wounded rat treated with standard cream (Dermazin) nominated as Silver Sulfadiazine as positive. Groups c, d and e represent the wounded rats that were treated with the dressing (cotton fabrics loaded with AgNPs at the concentrations $250 \mathrm{ppm}, 125 \mathrm{ppm}$ and 60 $\mathrm{ppm})$, respectively. The dressings $(1.5 \mathrm{~cm} \times 1.5 \mathrm{~cm})$ were changed daily.

During change of the dressings, wounds were inspected. The progressive changes in wound area were monitored planimetrically by tracing the wound margin on a graph paper every alternate day. The change in healing of wound, i.e. the measurement of wound area was expressed as unit $\left(\mathrm{mm}^{2}\right)$. The percentage reduction of original wound size was expressed as Wound Contraction.

Wound Contraction $\%=\frac{\text { Wound area day } 0-\text { wound area day } n}{\text { Wound area day } 0} \times 100$

In vivo acute anti-inflammatory: This acute effect was determined according to the method described by Winter $e t a l^{(14)}$. Twenty-four male albino rats were divided into four groups. Group 1 administrated the negative control group received $1 \mathrm{ml}$ saline. Group $2 \& 3$ displayed the one single oral dose of the tested AgNPs at two concentrations of $250 \mathrm{ppm}(0.25 \mathrm{ml}, 0.5 \mathrm{ml})$, respectively. Group 4 represents the reference drug (indomethacin $20 \mathrm{mg} / \mathrm{kg}$ rat). One hour later all the animals had a sub planter injection of $0.1 \mathrm{ml}$ of $1 \%$ carrageenan solution in saline, in the right hind paw and $0.1 \mathrm{ml}$ saline in the lift hind paw. Four hours after drugs administration, the rats were sacrificed. Both hind paws were excised and weighed separately. The percentage oedema was calculated according to the following equation:

$$
\text { Oedema } \%=\frac{\text { Weight of right paw }- \text { weight of left paw }}{\text { weight of left paw }} \times 100
$$

Egypt. J. Chem. 56, No. 2 (2013) 
The obtained data expressed as mean \pm standard deviation ${ }^{(15)}$ were statically analyzed using student's " $t$ " test ${ }^{(16)}$.

Toxicological studies: Detrmination of the lethal dose $50\left(\mathrm{LD}_{50}\right)$ of the AgNPs surrounded by alkali-dissolved starch was estimated according to the karber procedure ${ }^{(17)}$.

Preliminary experiments were done to determine the minimal lethal dose that kills all animals $\left(\mathrm{LD}_{100}\right)$ and the maximal dose that fails to kill any animal. Several doses at equal logarithmic intervals were chosen in between these two doses, each dose was injected in a group 6 mice's by subcutaneous injection. The mice were then observed for $24 \mathrm{hr}$ and symptoms of toxicity and mortality rates in each group were recorded and $\mathrm{LD}_{50}$ was calculated.

\section{Results and Discussion}

\section{Preparation of powdred silver nanoparticles}

Powdered as well as highly concentrated AgNPs (30000 ppm) were successfully prepared using alkali dissolved starch, which plays the dual role: reduction of Ag ions and stabilization of AgNPs formed thereof.

Treatment of starch with sodium hydroxide at higher concentration increases the swelling of the starch granules and produces more starch-O-Na. the stability of the formed AgNPs may be due to the presence of highly hydroxyl groups present at in skelton of starch molecules have the ability to coordinate with $\mathrm{Ag}$ ions leading to maintaining it in the smallest cluster. On the other hand, the reduction power of starch-O-Na for Ag ions converting it to AgNPs may also attributed to the presence of reducing groups at $\mathrm{C} 6$ of starch-O-Na molecules.

The appearance of yellow, light brown and dark brown colour in solution and mirror like illumination on the walls of conical flask clearly indicated the formation of AgNPs in the reaction medium. The colour of the colloidal solution dispersion is due to the excitation of surface Plasmon vibrations in the $\operatorname{AgNPs}^{(18-19)}$.

Figure 1 shows the UV-vis absorption spectroscopy for alkali dissolved starch and AgNPs colloidal solution after dilution the powder; AgNPs powder was diluted 1:100. It is clear that, the alkali dissolved starch has no absorption band along the wavelength while the band becomes stronger and more symmetrical with a pronounced bell shape at $\lambda_{\max } 417 \mathrm{~nm}$ in the case of AgNPs which were formed as result of both reduction of $\mathrm{Ag}^{+}$and stabilization of the resultant AgNPs by alkali dissolved starch. 


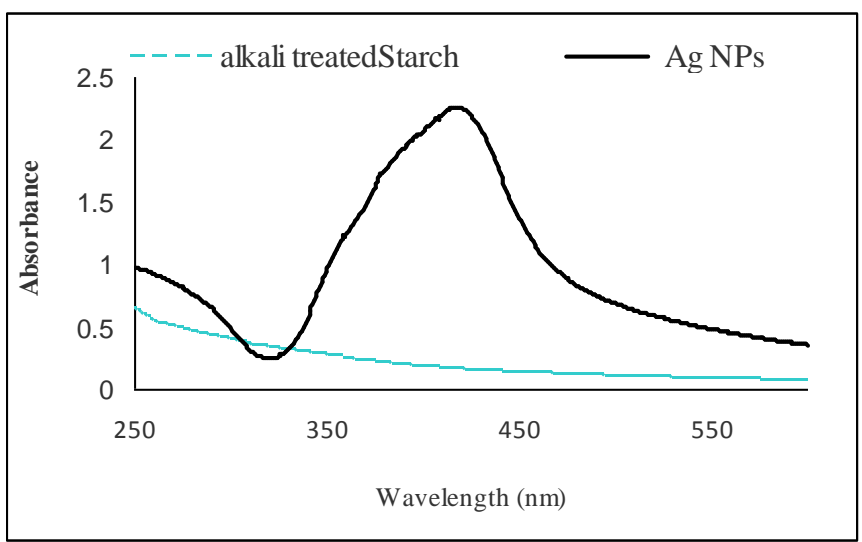

Fig. 1. UV-Vis spectroscopy of AgNPs stabilized by alkali dissolved starch.

The AgNPs were also investigated by TEM and their size distributions were measured using image J $1.45 \mathrm{~s}$ software. Figure $2 \mathrm{a}$, b displays a typical TEM micrograph and the particle size distribution of AgNPs. The TEM images clarify that the Ag NPs formed are characterized by being highly concentrated with spherical shape and extremely small size. TEM images visualize also the stabilization phenomenon of the highly concentrated AgNPs. Furthermore, the predominant Ag NPs size lies between 12 and $22 \mathrm{~nm}$.
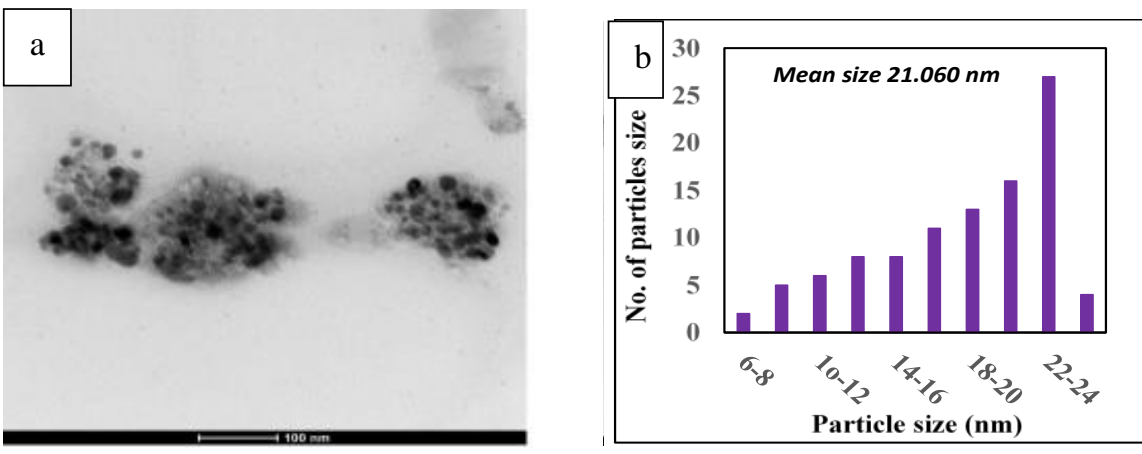

Fig. 2. a. TEM micrograph of AgNPs stabilized by alkali dissolved starch, b. histogram of silver nanoparticles size distribution.

Figure 3 a shows the particle size analyser and PdI of AgNPs while results of the zeta potential of the AgNPs colloidal solution are shown in Fig. 3b. Results of the particle size and polydispersity feature that the majority of particle size acquire a value of at $18 \mathrm{~nm}$ along with low PdI (0.163) indicating good uniformity of Ag NPs solution. 
The colloidal solution containing the as prepared Ag NPs was subjected to $\mathrm{ZP}$ measurement ( Fig. 3 b). According to such measurement, ZP attains a value $-28 \mathrm{mV}$, indicating high stability for the colloidal solution. The negative $\mathrm{ZP}$ of the synthesized Ag NPs is most probably owing to capping of the particles by starch molecules through interaction of the starch hydroxyls with AgNPs.
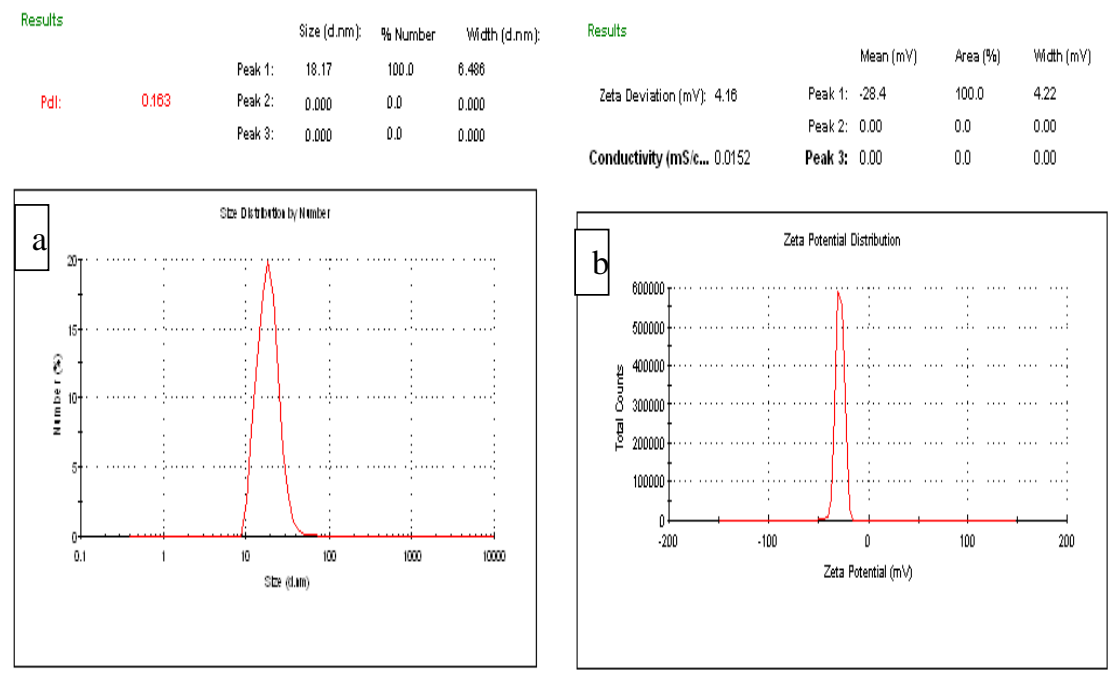

Fig. 3. a. Particle size analyzer and PdI of AgNPs obtained by DLS. b. Zeta potential of AgNPs.

A salient feature of the AgNPs dispersed in their colloidal solution or synthesized in the powder form is the stability. Stated in other words, AgNPs colloidal solution is stable and so does the powdered AgNPs. This can be verified through a close examination of the average size and PdI of AgNPs both of which are in conformation with the results of TEM images and particle size distribution. Stability of AgNPs in their colloidal solution is also in accordance with the results of our previous report ${ }^{(13)}$.

\section{Scanning electron micoscopy (SEM)}

Figure $4 \mathrm{a}, \mathrm{b}, \mathrm{c}$ and $\mathrm{d}$ represent the SEM images of the samples of cotton fabrics before and after loading with AgNPs. As evident surface roughness characterizes the samples loaded with AgNPs. For instance, 4 a depicts that the untreated cotton fabrics exhibit smooth surface whereas the surface of AgNPs loaded fabrics is rough and the surface roughness increases by increasing the amount of AgNPs loaded thereon. This can be ascribed to AgNPs deposited on the surface of cotton fabrics as illustrated in Fig. 4 b, c and d. 

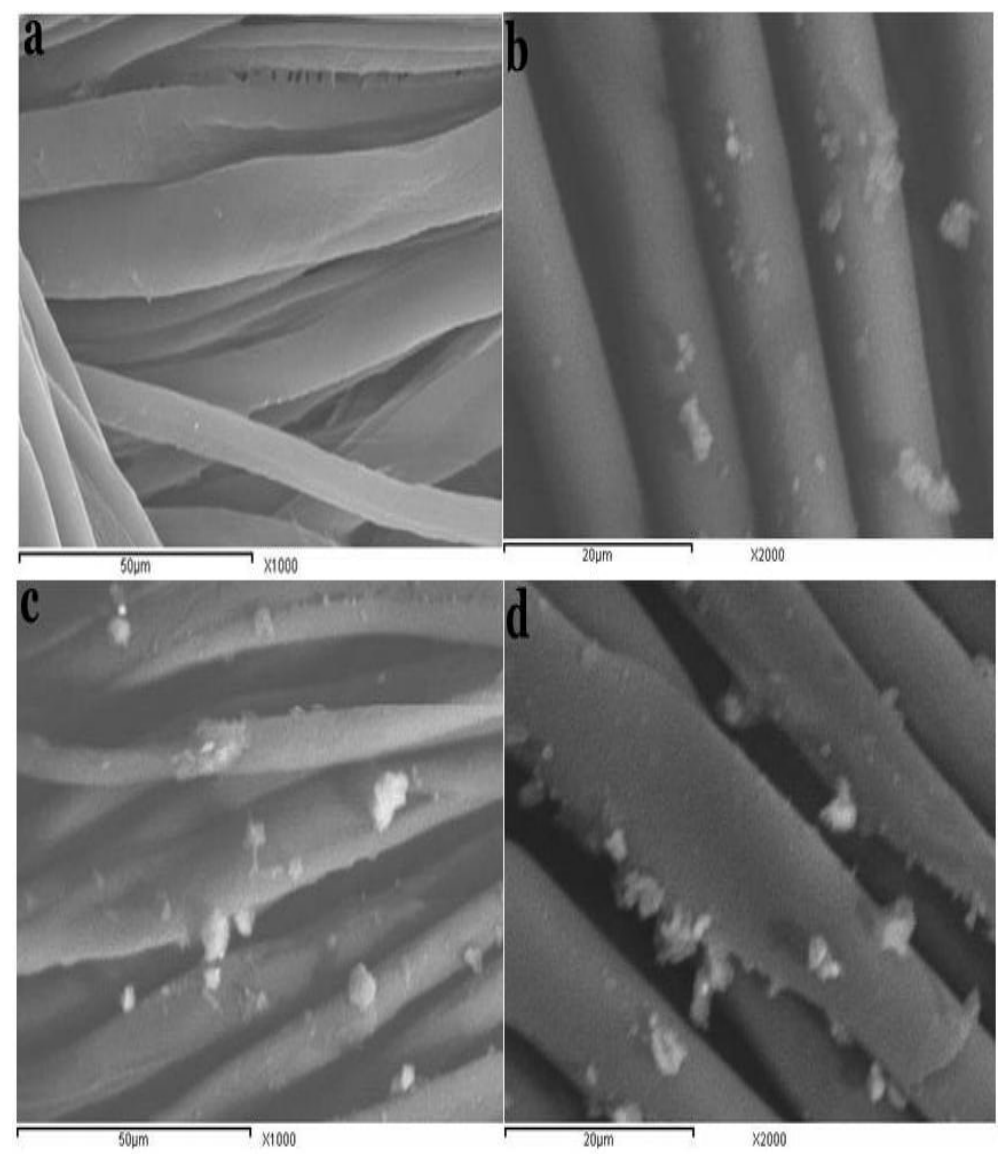

Fig. 4. SEM of (a) untreated cotton fabrics, (b,c and d) cotton fabrics treated with 60, 125 and $250 \mathrm{ppm}$ of AgNPs colloidal solution, respectively.

It is as well to report that AgNPs with varying diameters exist within the three concentrations of AgNPs loaded onto cotton fabrics. AgNPs as appeared in SEM micrographs are not spherical, but are irregularly shaped and much bigger in size due to aggregation of AgNPs.

The presence of the silver peak is also confirmed by Energy Dispersive spectroscopy ${ }^{(20)}$ (shown along with SEM image) of the corresponding fabric. Figure 5 discloses the EDX for cotton fabrics loaded with AgNPs at a concentration of $250 \mathrm{ppm}$. 


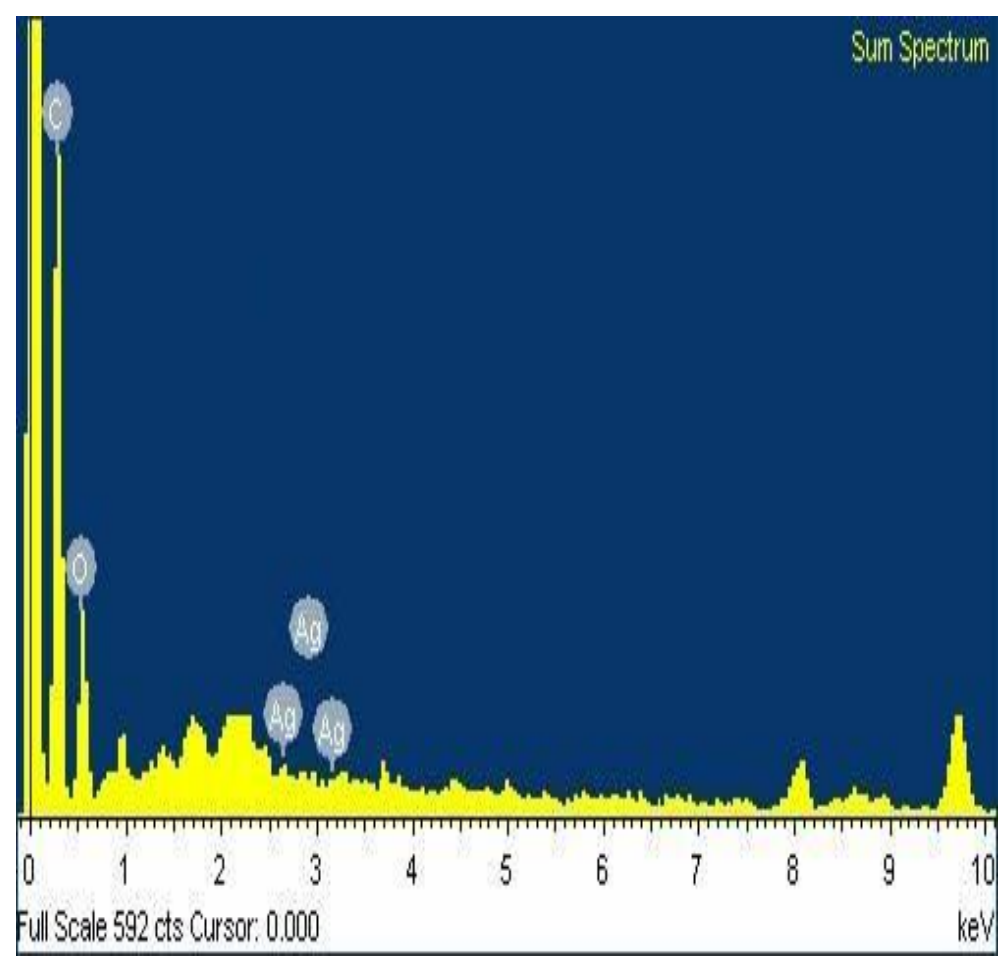

Fig. 5. EDX of cotton fabrics treated with $250 \mathrm{ppm}$ of AgNPs.

EDX spectrum (Fig.5) shows strong carbon and oxygen peaks, which could be attributed to the surrounding fabric material. Three peaks of silver in the spectrum appeared around $3 \mathrm{keV}$ indicate the existence of silver that was diffused into cotton fabrics. The results obtained from EDX spectrum together with those of the SEM images are strong evidence of the formation of AgNPs on the surface of cotton fabrics.

\section{Antimicrobial activity of fabrics treated with AgNPs colloidal solution}

Table 1 shows the antimicrobial activity of cotton fabrics treated with AgNPs colloidal solution. The fabrics were evaluated by diffusion method against two types of bacteria; Gram positive and Gram-negative ( $S$. aureus and E. coli, respectively) and one type of fungi (C. albicans). It is clear that the cotton fabrics treated with different concentrations of AgNPs exhibit inhibition zones.

The maximum growth of inhibition rings of $S$. aureus and E. coli were 10 and $13 \mathrm{~mm}$, respectively when the cotton fabrics treated with $250 \mathrm{ppm}$ AgNPs as compared with that of the untreated cotton fabrics; no inhibition zone could be observed with the untreated cotton fabrics. This clearly demonstrates that the 
antimicrobial activity is attributed to AgNPs diffused inside cotton fabrics and not to individual cotton fibres.

In the case of fungi (C. albicans), on the other hand, cotton fabrics treated with AgNPs at concentration of 60 and $125 \mathrm{ppm}$ fail to exert any inhibition zone. On the contrary increasing the concentration of AgNPs to $250 \mathrm{ppm}$ in the treating solution of cotton fabrics, the latter display an inhibition zone, the diameter of which attains a value of $6 \mathrm{~mm}$.

TABLE 1. Antimicrobial activity of treated cotton fabrics with AgNPs determined by inhibition zone method.

\begin{tabular}{|l|c|c|c|c|}
\hline \multirow{2}{*}{$\begin{array}{c}\text { Microorganisms } \\
\text { name }\end{array}$} & \multirow{2}{*}{$\begin{array}{c}\text { Untreated } \\
\text { cotton fabrics }\end{array}$} & \multicolumn{3}{|c|}{$\begin{array}{c}\text { Cotton fabrics treated with AgNPs } \\
\text { colloidal solution at aconcentration of }\end{array}$} \\
\cline { 3 - 5 } & & $250 \mathrm{ppm}$ & $125 \mathrm{ppm}$ & $60 \mathrm{ppm}$ \\
\hline E. coli & $0 \mathrm{~mm}$ & $10 \mathrm{~mm}$ & $9 \mathrm{~mm}$ & $8 \mathrm{~mm}$ \\
\hline S. aurous & $0 \mathrm{~mm}$ & $13 \mathrm{~mm}$ & $11 \mathrm{~mm}$ & $8 \mathrm{~mm}$ \\
\hline C. albicans & $0 \mathrm{~mm}$ & $6 \mathrm{~mm}$ & $0 \mathrm{~mm}$ & $0 \mathrm{~mm}$ \\
\hline
\end{tabular}

Results of Table 1 disclose that the Gram-negative bacteria $E$. coli is less sensitive to AgNPs as compared with Gram-positive bacteria $S$. aureus. The difference in sensitivity towards AgNPs between of Gram-positive bacteria and Gram-negative bacteria could be interpreted in terms of differences in their membrane structure with respect to thickness and constituents. The cell wall of the Gram-negative bacteria consists of lipids, proteins and lipopolysaccharides that provide effective protection against biocides whereas that of the Grampositive bacteria does not contain of lipopolysaccharides ${ }^{(21)}$.

The AgNPs have the smallest size and the largest surface area that makes that AgNPs not only interact with the surface of membrane, but can also penetrate inside the cells of bacteria ${ }^{(22)}$. The action of AgNPs on the bacteria is also due to the interaction with thiol group compounds found in the respiratory enzymes of bacterial cells thus inhibiting the respiration process in bacteria ${ }^{(23,24)}$. Moreover, AgNPs enter into bacteria cells and condensed DNA as a consequence, DNA is prevented from replication and cells from reproduction ${ }^{(23,24)}$.

\section{Wound healing activity of AgNPs}

The biological effects of AgNPs on wound healing appear to be manifolds. Table 2 shows the progress of wound healing induced by cotton fabrics treated with $\mathrm{AgNPs}(60,125$ and 250ppm) as compared with untreated cotton fabrics as a control group and Dermazin cream (standard drug) as treated group of animals. 
It is observed (Table 2), that the wound contracting ability of the cotton fabrics treated with AgNPs at different concentrations $(60,125$ and 250ppm) is significantly greater than that of the control (untreated cotton fabrics). It is also obsereved that, the wound healing of dressing containing Dermazin causes to marginal increment when compared with the cotton fabrics loaded with 250 ppm.

Results of Table 2 signify further that almost complete healing of treated animals could be achieved within 8 days when the dressing consists of Dermazin (-96.4\%) followed by the AgNPs treated cotton fabrics with concentration of $250 \mathrm{ppm}(-84.6 \%)$. Other cotton fabrics treated with lower concentrations of AgNPs $(125,60 \mathrm{ppm})$ display reasonable healing. It is also emphasized that, healing of wounds could be improved by using AgNPs without any scars.

This is most probably owing to continuous release of AgNPs which, then, slowly change to $\mathrm{Ag}^{+}$under the physiological system and and interact with bacterial cells present in the animals wounds, thus $\mathrm{Ag}^{+}$concentration will not be so high enough to cause damage of the normal human cells and can prolong the antimicrobial effect.

TABLE 2. Wound healing effect of AgNPs treated cotton fabrics.

\begin{tabular}{|c|c|c|c|}
\hline \multirow{2}{*}{ Treatments } & \multicolumn{3}{|c|}{ Percentage of change in thermal wound } \\
\cline { 2 - 4 } & Day 4 & Day 6 & Day 8 \\
\hline Control & +4.2 & +4.8 & +5.2 \\
\hline Standard drug & -70.4 & -81.6 & -96.4 \\
\hline Dressing 1 & -42.3 & -65.4 & -84.6 \\
\hline Dressing 2 & -41.7 & -54.2 & -70.8 \\
\hline Dressing 3 & -31.8 & -45.5 & -63.6 \\
\hline
\end{tabular}

where: control (untreated cotton fabrics), Standard drug (Dermazin), Dressing 1,2 and 3 (treated cotton fabrics with 250, 125 and 60 ppm, respectively).

Anti- inflammatory effect of AgNPs colloidal solution

Table 3 show the anti-inflammatory properties for two different doses $(0.5$ and $0.25 \mathrm{ml}$ ) of $250 \mathrm{ppm}$ AgNPs colloidal solution nominated AgNPs 1 and AgNPs 2, respectively compared to that of control groups (Saline) and standard drug (indomethacin).

It is seen (Table 3) that in animal models the inflammation disease decreases in the case of the AgNPs at the two different concentrations used. It is also seen that $0.5 \mathrm{ml}$ of $250 \mathrm{ppm} \mathrm{AgNPs}$ is more potent than that of $0.25 \mathrm{ml}$ of $250 \mathrm{ppm}$

Egypt. J. Chem. 56, No. 2 (2013) 
AgNPs. The percent of change were 55.9 \%, 49.3, respectively. The antiinflammatory effect of AgNPs at $0.5 \mathrm{ml} \mathrm{AgNPs}$ at a concentration of $250 \mathrm{ppm}$ dose is nearly similar to $20 \mathrm{ml}$ dose of the reference drug (indomethacin). The prepared AgNPs significantly reduce the degree of rat bow oedema and hence AgNPs can, indeed, reduce inflammation and its use in other inflammatory conditions is eagerly anticipated.

TABLE 3. Acute anti-inflammatory activity of AgNPs and indomethacin drug in male albiro rats $(n=6)$.

\begin{tabular}{|c|c|c|c|}
\hline \multirow{2}{*}{ Group } & \multirow{2}{*}{ Dose ml/kg } & \multicolumn{2}{|c|}{ Oedema \% } \\
\cline { 3 - 4 } & & Mean \pm S.D. & \% of change \\
\hline Control & - & $62.3 \pm 2.1$ & - \\
\hline AgNPs 1 & 0.25 & $31.6 \pm 0.9$ & $49.3 \%$ \\
\hline AgNPs 2 & 0.5 & $27.5 \pm 0.6$ & $55.9 \%$. \\
\hline Standard drug & 20 & $25.4 \pm 0.3$ & $59.2 \%$ \\
\hline
\end{tabular}

where: control (carrageenan), Standard drug (indomethacin), AgNPs 1, AgNPs 2 (concentration of AgNPs are $250 \mathrm{ppm}$ and $125 \mathrm{ppm}$, respectively).

\section{Toxicological effects of AgNPs colloidal solution}

A common problem with silver, whether nano or micro, is argyria, which is the irreversible ashen-gray discoloration of the skin, conjunctiva, and internal organs caused by continued exposure to silver or silver compounds.

The toxicological effect of AgNPs toward peritoneal macrophages was assayed. Macrophages were exposed to AgNPs at concentrations of 2.5, 5, 7.5, $10,12.5$ and $15 \mu \mathrm{g} / \mathrm{mL}$. The cell viability of AgNPs-treated macrophages is significantly constant at $10 \mu \mathrm{g} / \mathrm{mL}$. When the concentration increases to 12.5 $\mu \mathrm{g} / \mathrm{mL}$, the cell viability marginally reduces. Meanwhile the cell viability reduces dramatically when the concentration of AgNPs reaches $15 \mu \mathrm{g} / \mathrm{mL}$. Therefore, the MIC is considered to be $\leq 10 \mu \mathrm{g} / \mathrm{ml}$.

\section{Conclusion}

Powdered silver nanoparticles and highly concentrated solutions of AgNPs using alkali dissolved starch which act the dual role: as reduction for $\mathrm{Ag}^{+}$and stabilizer for AgNPs formed thereof. AgNPs colloidal solution having different concentrations $(60,125$ and $250 \mathrm{ppm})$ was prepared from stock solution having highly concentration $30000 \mathrm{ppm}$ AgNPs. The AgNPs colloidal solutions were used for treatment of cotton fabrics as per the pad-dry-cure technique. Cotton 
fabrics loaded with these three different concentrations of AgNPs colloidal solutions were evaluated for various medical applications, namely, antimicrobial, wound healing, anti-inflammatory as well as toxicity. The antimicrobial efficacy of dressing containing $250 \mathrm{ppm}$ AgNPs was more effective against microorganisms including bacteria and fungi than that of dressing containing 60 and $125 \mathrm{ppm}$ as indicated by the inhibition zone. The wound healing of dressing containing the highest content of AgNPs (250 ppm) acquire the greatest potent healing, which is nearly similar to the controlled cream (Dermazin). It was also found that wound healing is intimately linked to inflammation in normal circumstances as various inflammatory mediators are secreted to modulate the healing process within wounds. The obedema percent of $250 \mathrm{ppm} \mathrm{AgNPs} \mathrm{was}$ nearly the same as appeared in the case of standard drug (indomethacin). The MIC) for the produced AgNPs on subsequent experiments was $\leq 10 \mu \mathrm{g} / \mathrm{mL}$. The antimicrobial wound dressing of AgNPs treated cotton fabrics is proposed to have promising potential in smart textiles, medical purposes as well as in various biological fields.

\section{References}

1. Slama, T., Gram-negative antibiotic resistance: there is a price to pay. Critical Care, 12 (Suppl 4), 1-7 (2008).

2. Ivan, D., et al., Bioactive surface modifications for dental and orthopedic implants, In: Tissue Engineering and Regenerative Medicine, CRC Press. p. 125-160 (2012).

3. Fu, J., et al., Construction of antibacterial multilayer films containing nanosilver via layer-by-layer assembly of heparin and chitosan-silver ions complex. Journal of Biomedical Materials Research Part A, 79A(3), p. 665-674 (2006).

4. Huang, H., Yuan, Q. and Yang, X., Preparation and characterization of metalchitosan nanocomposites. Colloids and Surfaces B: Biointerfaces, 39(1-2), p. 31-37 (2004).

5. Slawson, R., Trevors, J. and Lee, H., Silver accumulation and resistance in Pseudomonas stutzeri. Archives of Microbiology, 158(6), 398-404 (1992).

6. Travan, A., et al., Non-cytotoxic Silver Nanoparticle-Polysaccharide Nanocomposites with Antimicrobial Activity. Biomacromolecules, 10(6), 1429-1435 (2009).

7. Sondi, I. and Salopek-Sondi, B., Silver nanoparticles as antimicrobial agent: a case study on E. coli as a model for Gram-negative bacteria. Journal of Colloid and Interface Science, 275(1), 177-182 (2004). 
8. Prabhu, S. and Poulose, E., Silver nanoparticles: mechanism of antimicrobial action, synthesis, medical applications, and toxicity effects. International Nano Letters, 2(1), $1-10$ (2012).

9. Prema, P. and Raju, R., Fabrication and characterization of silver nanoparticle and its potential antibacterial activity. Biotechnology and Bioprocess Engineering, 14(6), 842-847 (2009).

10. Bhainsa, K.C. and D'Souza, S.F., Extracellular biosynthesis of silver nanoparticles using the fungus Aspergillus fumigatus. Colloids and Surfaces B: Biointerfaces, 47(2), 160-164 (2006).

11. Lee, H.J., Yeo, S.Y. and Jeong, S.H., Antibacterial effect of nanosized silver colloidal solution on textile fabrics. Journal of Materials Science, 38(10), 2199-2204 (2003).

12. Sundaramoorthi, C., Devarasu, S. and Vengadesh prabhu, K., Antimicrobial and wound healing activity of silver nanoparticles synthesized from streptomyces aureofaciens. International Journal of Pharma Research and Development, 2(12), 6975 (2011).

13. Hebeish, A. et al., Nanostructural features of silver nanoparticles powder synthesized through concurrent formation of the nano-sized particles of both starch and silver. Carobohydrate Polymers, in press (2013).

14. Winter Ca, R.E. and Nuss Gw., Carrageenin-induced edema in hind paw of the rat as an assay for antiiflammatory drugs, in Proc Soc Exp Biol Med. 1544-7 (1962).

15. Varum, K.M., et al., Carbohydr. Res., 211, 17 (1991).

16. Snedecor, G.W. and Cochran, W.C. Statistical Methods, Iowa State Press Ames (1971).

17. Karber, G., Contribution to the collective treatment of pharmacological serial experiments. Archiv for Experimentelle Pathologie und Pharmakologie, 162, 480-483 (1931).

18. El-Rafie, M.H., et al., Environmental synthesis of silver nanoparticles using hydroxypropyl starch and their characterization. Carbohydrate Polymers, 86(2), 630635 (2011).

19. Hebeish, A., et al., Highly effective antibacterial textiles containing green synthesized silver nanoparticles. Carbohydrate Polymers, 86(2), 936-940 (2011). 
20. Shi, Q., et al., Durable antibacterial Ag/polyacrylonitrile (Ag/PAN) hybrid nanofibers prepared by atmospheric plasma treatment and electrospinning. European Polymer Journal, 47(7), 1402-1409 (2011).

21. Feng, Q.L., et al., A mechanistic study of the antibacterial effect of silver ions on Escherichia coli and Staphylococcus aureus. Journal of Biomedical Material Research, 52(4), 662-668 (2000).

22. Kaur, J. and Tikoo, K., Evaluating cell specific cytotoxicity of differentially charged silver nanoparticles. Food and Chemical Toxicology, 51(0), 1-14 (2013).

23. Klasen, H.J., Historical review of the use of silver in the treatment of burns. I. Early uses. Burns, 26(2), 117-130 (2000).

24. Li, W.-R., et al., Antibacterial activity and mechanism of silver nanoparticles on Escherichia coli. Applied Microbiology and Biotechnology, 85(4), 1115-1122 (2010).

(Received 25/6/2013;

accepted 6/8/2013) 


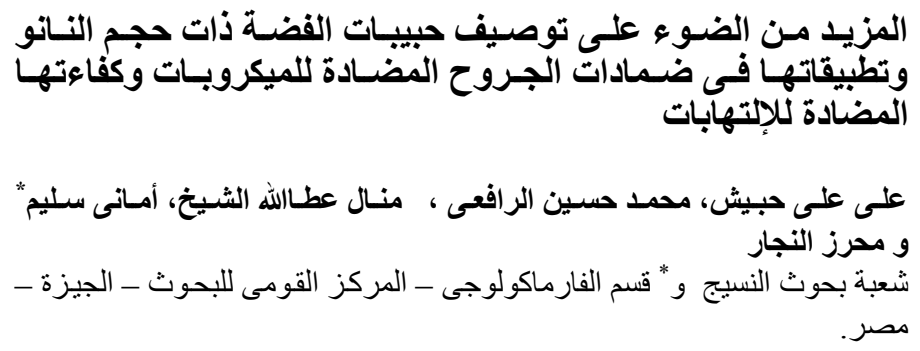

أمكن بنجاح تحضير حبيبات الفضة ذات حجم النانو بإضافة نترات الفضة إلى في

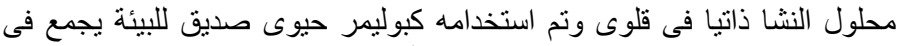

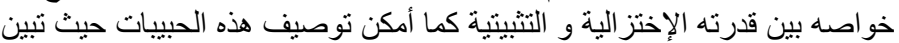

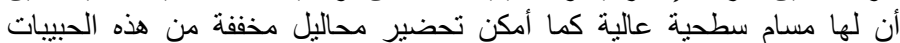

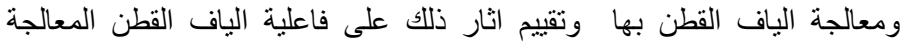

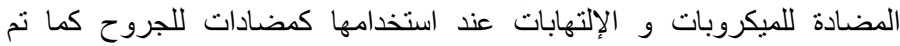

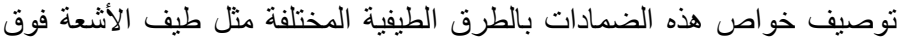

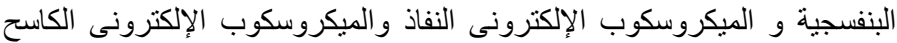

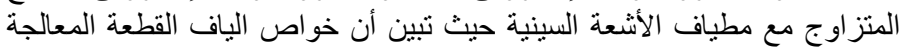

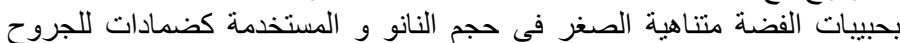

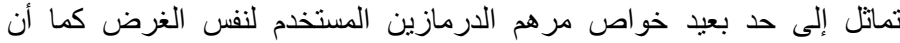

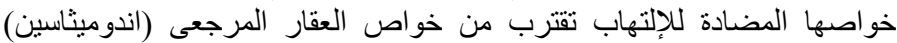

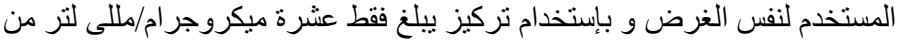

حبيات النانو فضة. 
A. Hebeish et al

Egypt. J. Chem. 56, No. 2 (2013) 